\title{
«AFINIDADES ELECTIVAS» ENTRE LITERATURA Y SOCIOLOGÍA: EL SUICIDIO DE ANDRÉS HURTADO EN EL ÁRBOL DE LA CIENCIA COMO EJEMPLO DE SUICIDIO ANÓMICO ${ }^{1}$
}

\author{
FRANCISCO FUSTER GARCÍA \\ Universidad de Valencia \\ francisco.fuster-garcia@uv.es
}

\section{RESUMEN}

El objetivo del presente trabajo es analizar el comportamiento social de Andrés Hurtado, personaje protagonista de la novela de Pío Baroja El árbol de la ciencia (1911). Se pretende reconstruir la trayectoria del personaje literario analizando la actitud de anomia y de individualismo radical que lo caracteriza. Para ello, hemos estudiado el suicidio del protagonista de la novela desde una perspectiva interdisciplinaria, que combina el análisis de la novela de Baroja y del caso específico de suicidio del personaje protagonista, con el análisis sociológico del fenómeno del suicidio, tal y como fue estudiado y sistematizado por Émile Durkheim en su obra Le Suicide (El suicidio, 1897), con el propósito de demostrar que el caso del suicidio de Andrés Hurtado en la novela de Baroja puede ser considerado como un ejemplo paradigmático de un tipo de suicidio muy común en la Europa de fin de siglo: el llamado «suicidio anómico».

Palabras ClaVe: Pío Baroja, Durkheim, anomia, suicidio, crisis de fin de siglo.

\footnotetext{
${ }^{1}$ Quiero expresar mi agradecimiento a los profesores del Departamento de Historia Contemporánea de la Universidad de Valencia, Anaclet Pons y Justo Serna, directores del trabajo de investigación del que es deudor este artículo. Igualmente, agradezco a la profesora del Departamento de Sociología y Comunicación de la Universidad de Salamanca, Irene Martínez, su lectura atenta del texto y sus atinados consejos y sugerencias.
} 


\section{ABSTRACT}

The aim of this work is to analyze the social behavior of Andrés Hurtado, main character of Pío Baroja's novel El árbol de la ciencia (1911). It is expected to reconstruct the course of the literary character through the analysis of his characteristic attitude of anomie and radical individualism. In order to this aim, we have studied the suicide of the main character of the novel from an interdisciplinary perspective which combines the analysis of Baroja's novel and the specific suicide case of his main character, with the sociological analysis of the suicide phenomenon, as it was studied and systematized by Émile Durkheim in his work Le Suicide (1897), in order to prove that Andres Hurtado's suicide case in Baroja's novel may be considered as a paradigmatic case of a kind of suicide very common in Europe's end-of-century: the so-called «anomic suicide».

Key Words: Pío Baroja, Durkheim, anomie, suicide, end-of-century crisis.

\section{LITERATURA Y SOCIOLOGÍA: UN MATRIMONIO BIEN AVENIDO}

Autores como José María González García ${ }^{2}$ o Irene Martínez ${ }^{3}$ han defendido en varios momentos y en distintos lugares el diálogo entre sociología y literatura, basándose en la coincidencia que se da a veces - la «afinidad electiva» - entre la obra sociológica y la literaria a la hora de abordar - cada una con sus medios o su método - un determinado tema u objeto de estudio. A diferencia de otros sociólogos que han estudiado o han trabajado con fuentes literarias considerándolas siempre como obras menores en cuanto a su potencial explicativo, como obras subsidiarias y dependientes siempre de la teoría sociológica, estos autores han abogado por un tratamiento de la obra literaria que le conceda una mayor importancia y que sitúe a la literatura y a la sociología como dos disciplinas complementarias cuya interacción puede ayudarnos a matizar y enriquecer nuestra comprensión de determinado fenómeno social o de determinado comportamiento o actitud del individuo en la sociedad moderna.

A nivel temático o de contenidos, el propio González García ha afirmado que quizá en lo que más han coincidido sociología y literatura ha sido en que ambas, cada una desde su perspectiva, han tratado de describir el comportamiento del hombre moderno en la sociedad burguesa industrializada, exactamente el ámbito en el que se produce la crisis de fin de siglo y en el que escribe Pío Baroja buena parte de su obra:

${ }^{2}$ GONZÁLEZ GARCÍA, José María (1988), La máquina burocrática. Afinidades electivas entre Max Weber y Kafka, Madrid, Visor; idem (1992) Las huellas de Fausto. La herencia de Goethe en la sociología de Max Weber, Madrid, Tecnos, 1992.

3 MARTÍNEZ SAHUQUILLO, Irene (1994), «William Morris y la crítica a la sociedad industrial: una síntesis singular de radicalismo y marxismo» en REIS: Revista Española de Investigaciones Sociológicas, $\mathrm{n}^{\circ}$ 66, $\mathrm{pp}$. 171-180; idem (1998) «Anomia, extrañamiento y desarraigo en la literatura del siglo XX: un análisis sociológico» en REIS: Revista Española de Investigaciones Sociológicas, ${ }^{\circ}$ 84, pp. 223-242; idem (2001), La revuelta contra la civilización. D.H.Lawrence y el romanticismo antimoderno, Madrid, Centro de Investigaciones Sociológicas. 
Literatos y sociólogos, literatura y sociología, compiten desde hace ciento cincuenta años en describir e interpretar la sociedad burguesa, en analizar las consecuencias de la industrialización y en ofrecer al hombre moderno una orientación de su conducta y de su ser-enel-mundo (GONZÁLEZ GARCÍA, 1988: 20).

Desde un punto de vista metodológico, la literatura puede proporcionar ejemplos concretos de estudio, mientras que la sociología nos proporcionaría el marco general, menos atento a los casos individuales y más centrado en los comportamientos y el devenir de las sociedades. El sociólogo estudia la norma y el escritor nos proporciona un ejemplo de aplicación de esa norma, convirtiéndose ambos en intérpretes de una misma realidad:

El creador literario se convierte, así, en un intérprete, como el sociólogo, de la realidad social y los acontecimientos históricos que la atraviesan aunque, en oposición a éste, no le interesa tanto descubrir tendencias generales como profundizar en los casos particulares en los que una tendencia general se manifiesta; su motivación corre, así, en sentido contrario a la regla durkheimiana que invita a desentenderse de las manifestaciones individuales de un fenómeno social (MARTÍNEZ SAHUQUILLO, 1998: 226).

Ejemplo claro de este uso de la literatura por parte de la sociología lo encontramos en la obra de importantes sociólogos como Norbert Elias. En alguna de sus obras más destacadas, el autor de El proceso de la civilización recurrió al empleo de textos literarios como recurso a partir del cual extraer ejemplos prácticos que facilitaran la comprensión de la teoría sociológica, por lo general tendente a la abstracción y la elaboración de teorías complejas. Como ha dicho González García para el caso del sociólogo alemán, Elias supo usar críticamente las novelas, sacando provecho de su vertiente sociológica:

Por último, nos encontramos también en la obra de Norbert Elias con el intento consciente de hacer hablar sociológicamente a los textos literarios, con la búsqueda deliberada de la explicación de relaciones sociales a partir del análisis de textos literarios, con la tesis formulada de una manera explícita en Estudios sobre los alemanes, según la cual las novelas, utilizadas críticamente, pueden ayudar a poner ante nuestros ojos a una sociedad del pasado con sus estructuras de poder ${ }^{4}$.

Lo que pretendo en este trabajo es intentar combinar con éxito el análisis de un fenómeno social - el suicidio - que muchos autores han asociado al malestar y el desencanto, a la anomia que invade muchas esferas de la sociedad finisecular europea. Por una parte, la teoría expuesta por el sociólogo francés Émile Durkheim en su obra El suicidio, en la que el autor obvia la casuística individual y describe el suicidio provocado por la anomia como un hecho social, me servirá para estudiar, desde un nivel de análisis más general, el comportamiento del individuo moderno y sus respuestas ante la crisis de valores que se produce durante el final de siglo. Por otra parte, la lectura de la novela de Baroja me será útil para comprender esta misma realidad desde una perspectiva mucho más concreta, casi microhistórica. El hecho de centrarme en el caso concreto de Andrés

${ }^{4}$ GONZÁLEZ GARCÍA, José María (1994), «Norbert Elias: literatura y sociología en El proceso de la civilización» en REIS: Revista Española de Investigaciones Sociológicas, n ${ }^{\circ} 65$, pp. 55-77, cita en p. 72. 
Hurtado y de su entorno más inmediato, me permitirá rastrear en todas sus actitudes un ejemplo paradigmático de comportamiento de un individuo de esa misma sociedad estudiada por los sociólogos.

\section{EL INDIVIDUO MODERNO Y LA CRISIS DE FIN DE SIGLO}

El ambiente de degradación moral y crisis de valores que caracteriza a la sociedad europea y española de finales del siglo XIX y principios del siglo XX ejerce una notable presión e influencia sobre el comportamiento del individuo moderno, especialmente del individuo urbano. El avance del capitalismo industrial y de la tecnología moderna va a propiciar la aparición de grandes aglomeraciones demográficas y la consolidación de una sociedad urbana en cuyo espacio público conviven la burguesía triunfante y el lumpen masivo, la aristocracia decadente y el hampa marginal.

El advenimiento de la llamada «sociedad de masas» provoca un cierto shock psicológico en un individuo que, acostumbrado a interrelacionarse con un círculo reducido de personas, ve como de pronto se halla inmerso en medio de multitudes y muchedumbres de seres anónimos que comparten su mismo espacio vital, pasando de la familiaridad y la notoriedad al anonimato y la indiferencia. Es en ese momento cuando el individuo adquiere las formas de sociabilidad y las características psicológicas que desde entonces han caracterizado al individuo común en la sociedad moderna, especialmente en la urbana. Fruto de este cambio en el modelo social serán un conjunto de trastornos y disfunciones manifestadas por una serie de individuos que expresan de diferentes formas su inadaptación al medio y su incomprensión de esta nueva realidad. Términos como $a b u$ rrimiento, individualismo, aislamiento, anomia, desencanto, alienación o desarraigo, son sólo algunos de los conceptos y categorías de análisis que la sociología clásica ha empleado para describir esta sensación de pesimismo y malestar psicológico que se apodera del individuo durante el período finisecular y los años posteriores.

Son estas mismas sensaciones las que se desprenden de las palabras del escritor húngaro de fin de siglo, Max Nordau, quien en un par de ensayos de tinte sociológico y de títulos tan elocuentes como Las mentiras convencionales de nuestra civilización (1883) o Degeneración (1892), retrata un ambiente de decadencia que él mismo asocia con la idea de fin de siglo:

Más por estúpida que puede ser la frase «fin de siglo», el estado de espíritu que está destinada a definir existe de hecho en los grupos directores; la disposición del alma actual es extrañamente confusa, hecha a la vez de agitación febril y de triste desfallecimiento, de temor a lo porvenir y de alegría desesperada que se resigna; la sensación dominante es la de un hundimiento, la de una extinción ${ }^{5}$.

Según ha dicho Ricardo Gullón, el fin de siglo se nos presenta como un «período de revisión total, en el que nada, desde la teología a la geometría, deja de ponerse en duda, y el repudio de lo vigente se realiza sistemáticamente y a fondo» ${ }^{6}$. «La anarquía moral, o

\footnotetext{
5 NORDAU, Max (1902), Degeneración, Tomo I, Madrid, Librería de Fernando Fé, p. 5.
} 
lo que se describía como tal — ha dicho Eugen Weber para el caso de Francia-, subvertía las ideas y los valores que hasta entonces se daban por sentados, al menos en público. Se acabaron las creencias, el vicio se veía por todas partes» ${ }^{7}$. Es este ambiente de incertidumbre y cuestionamiento de los valores de la moral burguesa el que provocará en el individuo moderno habituado a ellos el tipo de reacciones y trastornos al que nos hemos referido antes. La abolición de normas y convenciones sociales provoca la anomia y la desorientación en un individuo que se siente alienado y que se refugia en sí mismo, en el individualismo y el aislamiento de la masa.

En su obra La división del trabajo social (1893), Durkheim establece una teoría según la cual, aquello que caracteriza definitivamente a la sociedad moderna es el tránsito del modelo social que él define como sociedad mecánica al modelo de lo que él llama sociedad orgánica, en una dicotomía que viene marcada por el factor que más distingue a un modelo del otro: el grado de extensión y complejidad en la división del trabajo. El individuo de esta sociedad que describe Durkheim se encuentra en muchos momentos presionado por una doble influencia. Por una parte, están las características de su propia personalidad, derivadas de cuestiones y coyunturas personales que solamente a él le afectan. Por otra parte, Durkheim habla de una serie de corrientes sociales que no emanan de ningún individuo, sino que se forman en una sociedad concreta y en un período histórico determinado. En el caso del fin de siglo europeo, la corriente social dominante es un sentimiento de malestar y pérdida de valores, germen de una descomposición social que provocaría el aumento del número de suicidios durante el período por él estudiado:

[...] no hay que dejarse deslumbrar por el brillante desarrollo de las ciencias, de las artes y de la industria, de que somos testigos; es muy cierto que se lleva a cabo, en medio de una efervescencia enfermiza, de cuyas dolorosas resultas cada uno de nosotros se resiente. Es muy posible, y hasta verosímil, que el movimiento ascensorial de los suicidios tenga por origen un estado patológico que acompañe a posteriori a la marcha de la civilización, pero sin ser su condición necesaria ${ }^{8}$.

3. El suicidio de Andrés Hurtado en el El Árbol de la ciencia de Pío Baroja: EJEMPLO DE SUICIDIO ANÓMICO

Los escasos catorce años que separan la publicación de El suicidio (1897) de Durkheim y El árbol de la ciencia (1911) de Pío Baroja indican que ambos autores reflejaron en sus escritos, uno en forma de elaboración teórica documentada y el otro en forma de ficción novelada, el ambiente de crisis y transformación de la sociedad de fin de siglo. En este sentido, esta coincidencia cronológica es una primera razón para justificar este estudio comparativo. Sin embargo, la razón fundamental de tomar el caso de Andrés Hurtado como ejemplo de lo que Durkheim llamó «suicidio anómico» tiene más que ver con las semejanzas que encontramos entre, por un lado, los rasgos que según Durkheim se

\footnotetext{
${ }^{6}$ GULLÓN, Ricardo (1969), La invención del 98 y otros ensayos, Madrid, Gredos, p. 12.

7 WEBER, Eugen (1989), Francia, fin de siglo, Madrid, Debate, p. 22.

${ }^{8}$ DURKHEIM, Émile (2008), El suicidio, Madrid, Akal, pp. 412-413.
} 
asocian a esta modalidad de suicidio y, por otro, las características con las que Baroja describe la vida mental de su personaje protagonista.

Para poder entender el episodio del suicidio del protagonista de El árbol de la ciencia es imprescindible conocer antes, aunque sea de forma resumida, cuáles son los antecedentes del personaje en aquello que se refiere a su carácter psicológico, a su personalidad y a su forma de relacionarse con entidades sociales superiores, ya sea su familia o la gente que le rodea en los distintos lugares por los que transita en la novela. Además de contextualizar el episodio del suicidio, que sólo ocupa la página final de la novela y que Baroja describe de una forma muy somera, sin apenas detalles sobre el escenario físico del acto, este repaso a la personalidad de Andrés Hurtado nos servirá para ver si en ella se reproducen, como así sucede, algunas de las actitudes y los trastornos - aislamiento, aburrimiento, desarraigo, pesimismo, individualismo, anomia - que convierten al personaje en un tipo literario propio de la literatura finisecular.

El primer síntoma de la personalidad individualista de Andrés Hurtado lo encontramos ya en las primeras páginas de la obra. Tras dos breves capítulos en los que Baroja describe al lector el ambiente universitario del Madrid de fin de siglo a través de la mirada de Andrés, los dos siguientes capítulos — «Andrés Hurtado y su familia» y «En el aislamiento» - nos introducen en la vida familiar del protagonista y ya nos hablan de su tendencia al aislamiento:

En casi todos los momentos de su vida, Andrés experimentaba la sensación de sentirse solo y abandonado (p. 379) .

Esta sensación de aislamiento y desarraigo está presente a lo largo de la novela. En la construcción que hace Baroja del carácter de Hurtado se unen factores familiares y factores sociales. En el plano familiar, desde las primeras páginas descubrimos una serie de malas experiencias que marcan la trayectoria del personaje. En primer lugar, la muerte prematura de la madre:

La muerte de su madre le había dejado un gran vacío en el alma y una inclinación por la tristeza (p. 379).

O, en el ambiente del hogar de los Hurtado, la tibia relación de Andrés con algunos de sus hermanos y la pésima relación con su padre:

[Andrés Hurtado] quería apasionadamente al hermano pequeño; tenía afecto por Pedro y por Margarita, aunque con ésta reñía constantemente; despreciaba a Alejandro y casi odiaba a su padre; no le podía soportar: le encontraba petulante, egoísta, necio, pagado de sí mismo.

Entre padre e hijo existía una incompatibilidad absoluta, completa; no podían estar conformes en nada. Bastaba que uno afirmara una cosa para que el otro tomara la posición contraria (p. 381).

9 Todas las citas de El árbol de la ciencia, seguidas del número de página entre paréntesis, corresponden a la edición incluida en: BAROJA, Pío (1998), Obras Completas, Vol. VIII, Barcelona, Círculo de Lectores - Galaxia Gutemberg. 
Estos factores familiares influirán en la personalidad de Andrés Hurtado potenciando ese estado anímico de indolencia y abandono:

Se sentía aislado de la familia, sin madre, muy solo, y la soledad le hizo reconcentrado y triste (p. 382).

En otros pasajes de la novela, Baroja hace referencia al aislamiento social de Andrés Hurtado, a su notable insociabilidad y a su total indiferencia respecto al mundo exterior:

Andrés no quería salir a la calle; sentía una insociabilidad intensa. Le parecía una fatiga tener que conocer a nueva gente.

-Pero, hombre, ¿no vas a salir? - le preguntaba Margarita.

-Yo, no. ¿Para qué? No me interesa nada de cuanto pasa fuera (p. 459).

Complementaria de esta tendencia al aislamiento en la personalidad de Andrés Hurtado es su innata sensación de desarraigo, de desapego respecto al lugar que ocupa. A lo largo de las páginas de la novela, son distintos y muy diversos los destinos y espacios en los que el personaje intenta encontrar acomodo. Allá donde se traslada, todo se le antoja absurdo y superfluo, todo le asfixia y le coarta. Durante sus primeros días de clases de Medicina en Madrid ya manifiesta su contrariedad por lo que él juzga un ambiente indigno e impropio del ámbito universitario:

Andrés Hurtado, los primeros días de clase, no salía de su asombro. Todo aquello era demasiado absurdo. Él hubiese querido encontrar una disciplina fuerte y al mismo tiempo afectuosa, y se encontraba con una clase grotesca, en que los alumnos se burlaban del profesor. Su preparación para la ciencia no podía ser más desdichada (p. 379).

Si esto sucede en Madrid, su juicio sobre el resto de escenarios de la novela por los que transita tampoco es mucho más benévolo. Cuando conoce que su hermano pequeño, Luisito, padece tuberculosis, decide planear su instalación en un pueblo de los alrededores de Valencia, con el ánimo de que un cambio en el clima ayude al pequeño a pasar el bache de la enfermedad. Después de un primer viaje de reconocimiento de Andrés, parte de la familia se traslada al pueblo para cuidar de Luisito. Pese a que en principio todo parece estar a su gusto, pronto se empieza a sentir incómodo. La vida del pueblo le parece «en muchas cosas absurda» (p. 455) y poco a poco empieza a sentir un agobio que le empuja a un nuevo cambio de aires: torado.

Al acercarse mayo, Andrés le dijo a su hermana que iba a Madrid a examinarse del doc-

- ¿Vas a volver? - le preguntó Margarita.

-No sé; creo que no.

-Qué antipatía le has tomado a esta casa y al pueblo. No me lo explico.

- No me encuentro bien aquí.

-Claro. ¡Haces lo posible por estar mal! (p. 461)

Otro capítulo en la historia del desarraigo de Andrés Hurtado es el lapso de tiempo que pasa en Alcolea del Campo, el pueblo manchego en el que ejerce de médico titular 
durante una temporada. La sentencia con la que Baroja abre el capítulo titulado «Alcolea del Campo» será todo un presagio de la inadaptación que el protagonista sufrirá en Alcolea y sintetiza perfectamente la opinión de Andrés Hurtado sobre el pueblo:

Las costumbres de Alcolea eran españolas puras, es decir, de un absurdo completo (p. 498).

Pese a esta mala experiencia rural, la vuelta a Madrid no cambia el juicio de Andrés, que en conversación con el personaje de Montaner, un viejo amigo de la facultad, insistirá en su incapacidad para adaptarse al medio urbano:

-Es triste todo esto. Siempre en este Madrid la misma interinidad, la misma angustia hecha crónica, la misma vida sin vida, todo igual.

-Sí, esto es un pantano - murmuró Montaner (p. 528).

La única excepción a la regla la encontramos en el pueblo de Burgos al que Andrés Hurtado se traslada, después de terminar el doctorado y leer la tesis, para ejercer de médico sustituto durante dos meses del verano. Recién doctorado y libre de cualquier carga familiar y social, ése será el único lugar de la novela en el que protagonista se sentirá a gusto. Baroja llega a hablar incluso, en un claro intento de contrastar realidades, de serenidad y de alegría. Eso sí, este oasis de felicidad es hábilmente usado por Baroja, que corta esa descripción idílica con el anticlímax que supone el conocimiento por parte de Andrés Hurtado de la noticia de la muerte en el pueblo de su hermano Luisito. Con este contraste de sensaciones magistral, Baroja muestra la tristeza vital del personaje; el único lugar en el que se encuentra bien el protagonista resulta el lugar elegido para recibir la peor noticia:

Andrés pudo comprobar que el pesimismo y el optimismo son resultados orgánicos como las buenas o las malas digestiones. En aquella aldea se encontraba admirablemente, con una serenidad y una alegría desconocidas para él; sentía que el tiempo pasaba demasiado pronto.

Llevaba mes y medio en este oasis, cuando un día el cartero le entregó un sobre manoseado, con letra de su padre. Sin duda había andado la carta de pueblo en pueblo hasta llegar a aquél. ¿Qué vendría allí dentro?

Andrés abrió la carta, la leyó y quedó atónito. Luisito acababa de morir en Valencia (p. 462).

El desarraigo de Andrés Hurtado no es más que un caso concreto de ese desarraigo que ya hemos dicho que caracteriza al individuo en la sociedad moderna. En su obra Un mundo sin hogar, los sociólogos Peter Berger, Brigitte Berger y Hansfried Kellner hablan precisamente del sentimiento que ellos llaman homelessnes o «falta de hogar», como uno de los principales efectos de la modernización ${ }^{10}$.

Quizá el mayor punto de desencuentro entre Andrés Hurtado y la sociedad de fin de siglo, en este caso no la sociedad urbana madrileña sino la sociedad rural de un pueblo,

${ }^{10} C f$. BERGER, Peter, BERGER, Brigitte y KELLNER, Hansfried (1979), Un mundo sin hogar, Santander, Sal Terrae. 
se produce durante su estancia en Alcolea del Campo. Hurtado critica las costumbres y tradiciones de un pueblo corrompido por el caciquismo y hundido en un ambiente de miseria moral, de egoísmo y de envidia insana. Una de las cosas que más recrimina el protagonista a los habitantes de Alcolea es su total indiferencia e insolidaridad respecto a lo social y lo colectivo, provocada por la desconfianza y el recelo. Ese instinto social de todo individuo, que según Durkheim complementa a la parte física, no lo encuentra Hurtado por ningún sitio:

El pueblo no tenía el menor sentido social; las familias se metían en sus casas, como los trogloditas en su cueva. No había solidaridad; nadie sabía ni podía utilizar la fuerza de la asociación. Los hombres iban al trabajo y a veces al casino. Las mujeres no salían más que los domingos a misa.

Por falta de instinto colectivo, el pueblo se había arruinado (p. 498).

Así pues, en la novela de Baroja, Alcolea es el ejemplo ideal de una sociedad en la que no existe esa autoridad moral que según Durkheim ha de ejercer cualquier sociedad sobre los individuos que la forman. El problema para Andrés Hurtado es que esta falta de autoridad es endémica en toda la sociedad española, o al menos así lo percibe él. Ni en Madrid, ni en Valencia, ni en ningún lugar encuentra el protagonista de El árbol de la ciencia una sociedad fuerte que imponga unas normas y unos límites a la acción -o la omisión de acción en su caso- del individuo.

Para Durkheim, la sociedad es el único poder moral superior al individuo y el único estamento autorizado para ejercer esa función moderadora de las pasiones y los intereses individuales; las instituciones sociales son las encargadas de establecer ese límite que los individuos no pueden rebasar. Cuando la sociedad se desintegra, como ocurre con la sociedad de fin de siglo que describe Baroja, el individuo también se desintegra; su parte social desaparece y sólo queda la parte física, los instintos naturales de egoísmo y supervivencia. Durkheim explica muy bien que en esta lucha constante por imponerse entre la personalidad individual y la personalidad colectiva, la alteración o sumisión de cualquiera de ambas partes redunda inmediatamente en la otra. Si el grupo se debilita, el individuo se exalta y viceversa. Por este mismo motivo, cuando mayor es la dependencia que los individuos tienen de la sociedad menor es la tendencia al suicidio; por contra, a mayor relajación de los lazos colectivos mayor propensión del individuo a desertar de su función social y a disponer libremente de su vida, incluso para terminar con ella:

Cuando la sociedad está fuertemente integrada tiene a los individuos bajo su dependencia, considera que están a su servicio y, por consiguiente, no les permite disponer de sí mismos a su antojo. Se opone, pues, a que eludan, por la muerte, los deberes que con ella tienen. Pero cuando rehúsan aceptar como legítima esta subordinación, ¿cómo puede aquélla imponer su supremacía? No tiene entonces la autoridad necesaria para retenerlos, si quieren desertar de su puesto y, consciente de su debilidad, llega hasta reconocerles el derecho a hacer libremente lo que ya no puede impedir (DURKHEIM, 2008: 214-215).

En medio de este panorama desolador que describe Andrés Hurtado, la reacción del protagonista de la novela de Baroja ante una realidad que no comprende y no comparte será la propia de muchos individuos del fin de siglo europeo y español: el refugio en un 
individualismo radical. En su caso particular, el individualismo se traducirá en un inquebrantable afán de independencia; una constante en los personajes de Baroja y un rasgo imprescindible de su literatura. En El árbol de la ciencia, el protagonista nos lo demuestra en varios momentos. En una conversación con su tío, el Doctor Iturrioz, en el cuarto capítulo de la novela, Andrés deja claro que no sabe qué hacer con su vida, que no tiene ningún plan preestablecido. Eso sí, a la independencia no puede renunciar jamás:

-Y entonces, ¿qué plan tienes?

- ¿Plan personal? Ninguno.

- ¡Demonio! ¿Tan pobre estás de proyectos?

-Sí, tengo uno: vivir con el máximo de independencia (p. 466).

Estando en Alcolea, Andrés vuelve a recordar sus principios. Al tiempo de vivir en el pueblo se le reproducen unos dolores artríticos crónicos. Él mismo se diagnostica la enfermedad y atribuye su recrudecimiento a «la castidad». Esto le lleva incluso a valorar la posibilidad - difícilmente contemplada en otras circunstancias - de casarse, como vía para poder compartir su vida con otra persona. Sin embargo, al reflexionar sobre la idea, no puede evitar pensar en la renuncia que eso supondría para su «independencia espiritual»:

Este dilema se presentaba ante él. Si quería vivir con una mujer, tenía que casarse, someterse. Es decir, dar por una cosa de la vida toda su independencia espiritual, resignarse a cumplir obligaciones y deberes sociales, a guardar consideraciones a su suegro, a su suegra, a su cuñado, cosa que le horrorizaba (p. 510).

Andrés Hurtado mantiene una conversación muy significativa con su tío Iturrioz a su vuelta de Alcolea. Cuando éste le recrimine que el fracaso de su experiencia en el pueblo se debe a su desmesurado individualismo y al hecho de haber intentado vivir al margen de todo el mundo, Andrés Hurtado lo negará, remitiendo a su tío a ese deseo de mantener intacta su independencia:

- [...] Intentar andar entre los hombres, en ser superior, como tú has querido hacer en Alcolea, es absurdo.

- Yo no he intentado presentarme como ser superior - replicó Andrés con viveza-. Yo he ido en hombre independiente. A tanto trabajo, tanto sueldo. Hago lo que me encargan, me pagan y ya está.

- Eso no es posible; cada hombre no es una estrella con su órbita independiente.

- Yo creo que el que quiere serlo lo es.

- Tendrá que sufrir las consecuencias.

- ¡Ah, claro! Yo estoy dispuesto a sufrirlas. El que no tiene dinero paga su libertad con su cuerpo; es una onza de carne que hay que dar, que lo mismo le pueden sacar a uno del brazo que del corazón. El hombre de verdad busca antes que nada su independencia (p. 525).

El individualismo de Andrés Hurtado, exacerbado por estos factores familiares y sociales, no deja de ser, sin embargo, un ejemplo de una de esas actitudes o posturas que adopta el individuo durante el fin de siglo y que, a partir de este momento, se convertirán en uno de los rasgos definitorios de la Modernidad. Como explicó el sociólogo alemán 
Georg Simmel en uno de los mejores y más finos análisis del comportamiento mental del individuo moderno, uno de los mayores problemas que ha tenido que afrontar el individuo partícipe de la Modernidad ha sido el de su incesante lucha por conservar su individualidad y su autonomía frente a una sociedad de masas que, por inercia y por naturaleza, ha tendido a igualar y a uniformizar a sus miembros:

Los más profundos problemas de la vida moderna manan de la pretensión del individuo de conservar la autonomía y peculiaridad de su existencia frente a la prepotencia de la sociedad, de lo históricamente heredado, de la cultura externa y de la técnica de la vida (la última transformación alcanzada de la lucha con la naturaleza, que el hombre primitivo tuvo que sostener por su existencia corporal $)^{11}$.

Es cierto que el caso de Andrés Hurtado es el de un individualismo desmedido y exagerado, pero es precisamente el tipo de caso que más relación guarda con el suicidio según Durkheim:

El individualismo excesivo no tiene tan sólo por resultado favorecer la acción de las cau-sas suicidógenas, es por sí mismo, una causa de ese género (DURKHEIM, 2008: 215).

El tipo de suicidio más conectado con esta actitud individualista es el suicidio que Durkheim llama egoísta; un tipo de suicidio que se da especialmente en sociedades en las que la autoridad moral del colectivo ha dejado de ejercer su ascendente sobre el individuo, como ocurría en muchas sociedades europeas del fin de siglo. Como dice Durkheim, en los grandes Estados modernos europeos, el individuo no siente la cercanía y la dependencia de una entidad superior que le contenga y le proteja:

El suicidio egoísta se origina porque la sociedad no tiene en todos sus puntos una integración suficiente para mantener a todos sus miembros bajo su dependencia. [...] Por consiguiente, la única forma de remediar el mal es dar a los grupos sociales bastante consistencia, para que mantengan más firmemente al individuo, y que éste, a su vez, se sostenga unido a ellos. Es preciso que se sienta más solidario de un ser colectivo que le ha precedido en el tiempo, que le sobrevive y que le supera por todas partes. En estas condiciones, cesaría de buscar en sí mismo el único objeto de su conducta, y comprendiendo que es el instrumento de un fin que le excede, percibiría que sirve para algo (DURKHEIM, 2008: 418-419).

Pero en el caso de Andrés Hurtado, a este individualismo de tendencia egoísta se suma otro factor: los síntomas inequívocos de anomia que muestra el protagonista de $E l$ árbol de la ciencia a lo largo de la novela y que convierten su suicidio en un suicidio anómico.

Si ya hemos visto algunos ejemplos del individualismo de Andrés Hurtado, de su tendencia al aislamiento y de su sentimiento de desarraigo, también podemos rastrear a lo largo de la novela opiniones y reflexiones que, unidas al resto de trastornos y comportamientos que ya hemos visto, nos permiten hablar de un comportamiento anómico en el

11 SIMMEL, Georg (1986), «Las grandes urbes y la vida del espíritu» en El individuo y la libertad. Ensayos de crítica de la cultura, Barcelona, Ediciones Península, 1986, pp. 247-261, cita en p. 247. 
protagonista de la novela de Baroja. La desorientación moral y la falta de un plan de vida, de un esquema y unas normas sociales de comportamiento, son una constante a lo largo de la obra. Ya en la primera parte de la novela Baroja describe este deseo del protagonista de hallar una verdad que guíe su desordenada existencia:

A Hurtado no le importaba nada la cuestión de los métodos y de las clasificaciones, ni saber si la sociología era una ciencia o un ciempiés inventado por los sabios; lo que quería encontrar era una orientación, una verdad espiritual y práctica al mismo tiempo (p. 400).

Pocas páginas después, se insiste en la misma idea. Durante su cuarto curso de carrera, Andrés y sus dos amigos de facultad, Montaner y Julio Aracil, acuden a unos cursos en el Hospital de San Juan de Dios. Lo que en principio iba a ser una experiencia enriquecedora acaba en una nueva decepción, en una nueva frustración de las expectativas y en una nueva reflexión de Hurtado, que vuelve a insistir en el sinsentido y la injusticia de la vida. La desorientación y la anomia crecen, provocándole un estado de sobreexcitación y enojo:

Pensaba que en la vida no había ni podía haber justicia. La vida era una corriente tumultuosa e inconsciente, donde todos los actores representaban una comedia que no comprendían; y los hombres, llegados a un estado de intelectualidad, contemplaban la escena con una mirada compasiva y piadosa.

Estos vaivenes en las ideas, esta falta de plan y de freno, le llevaban a Andrés al mayor desconcierto, a una sobreexcitación cerebral continua e inútil (pp. 408-409).

La incomprensión de Andrés Hurtado es la propia del sujeto anómico. Como dice Durkheim, el suicidio anómico es el suicidio de los incomprendidos y es un suicidio provocado por la frustración de las expectativas. Ante cualquier dificultad para cumplir sus deseos, el individuo anómico opta por la vía fácil del suicidio. El agobio y la insatisfacción permanente le obligan a acabar con su propia existencia, como medida última y desesperada:

Éste es el suicidio de los incomprendidos, tan frecuente en las épocas donde no hay clasificación reconocida. Otras veces, después de haber conseguido, durante cierto tiempo, satisfacer todos sus deseos y su gusto de cambio, viene a chocar de pronto contra una resistencia que no puede vencer, y se deshace con impaciencia de una existencia en la que se encuentra en adelante agobiado (DURKHEIM, 2008: 312).

A medida que avanza la novela, este estado de agobio y angustia irá creciendo. Los cambios de domicilio y de trabajo, la aparición de nuevos personajes y nuevas relaciones en la vida de Andrés; nada de esto será suficiente consuelo. No encuentra normas ni reglas a las que atenerse. Como hemos visto en Durkheim, la autoridad moral representada por la sociedad no es lo suficientemente fuerte y Hurtado sigue sin saber qué sentido dar a su existencia:

«¿Qué hacer? ¿Qué dirección darle a la vida?», se preguntaba con angustia. Y la gente, las cosas, el sol, le parecían sin realidad ante el problema planteado en su cerebro (p. 445). 
En este mismo sentido se expresa el protagonista en la cuarta parte de la novela, ocupada en su totalidad por el diálogo entre Andrés Hurtado y su tío Iturrioz. Son las páginas de mayor contenido filosófico de la novela y las que usa Baroja para separar ambas partes de la historia (la novela tiene siete partes; la primera ocupa tres, la segunda tres más y en medio está este capítulo). Durante su conversación con Iturrioz, Hurtado vuelve a manifestar a su tío que no encuentra ningún sentido al vivir, a lo que Iturrioz responde acusándole de un excesivo intelectualismo. En este diálogo, Iturrioz defiende una postura de pragmatismo y realismo, frente al idealismo de un Andrés Hurtado que trata de buscar en la ciencia una explicación racional del cosmos y del universo. Iturrioz insiste a su sobrino en que tiene que encontrar un plan personal de vida, algo a lo que agarrarse. Por su parte, Hurtado confiesa haber leído a Kant y a Schopenhauer y haber caído en un estado de anomia y desesperación:

- ¿Y qué? - replicó Andrés-. Uno tiene la angustia, la desesperación de no saber qué hacer con la vida, de no tener un plan, de encontrarse perdido, sin brújula, sin luz adonde dirigirse. ¿Qué se hace con la vida? ¿Qué dirección se le da? Si la vida fuera tan fuerte que le arrastrara a uno, el pensar sería una maravilla, algo como para el caminante detenerse y sentarse a la sombra de un árbol, algo como penetrar en un oasis de paz; pero la vida es estúpida, y creo que en todas partes, y el pensamiento se llena de terrores como compensación a la esterilidad emocional de la existencia.

-Estás perdido - murmuró Iturrioz-. Ese intelectualismo no te puede llevar a nada bueno (p. 467).

Quizá otro de los episodios en los que más claramente se manifiesta esta anomia de Andrés Hurtado sea el que se produce cuando el protagonista recibe la noticia de la muerte de su hermano pequeño, Luisito, víctima de una tuberculosis. Como ya hemos dicho antes, Baroja sitúa este episodio en un momento clave de la novela. Hurtado disfruta en un pueblo de Burgos, de unos días felices ejerciendo como médico durante el verano. En medio de esta paz, recibe una carta procedente de Valencia en la que su hermana Margarita, que se había quedado en el pueblo de Valencia al cuidado del hermano pequeño, le comunica la muerte de Luisito. A la primera reacción de sorpresa y estupor de Andrés Hurtado, le sigue una reacción de anomia e indiferencia ante el dolor:

Andrés abrió la carta, la leyó y quedó atónito. Luisito acababa de morir en Valencia.

[...] La noticia le produjo un gran estupor. El alejamiento, el haber dejado a su marcha a Luisito sano y fuerte, le impedía experimentar la pena que hubiese sentido cerca del enfermo. Aquella indiferencia suya, aquella falta de dolor, le parecía algo malo. El niño había muerto; él no experimentaba ninguna desesperación. ¿Para qué provocar en sí mismo un sufrimiento inútil? Este punto le debatió largas horas en la soledad (p. 462).

Cuando esta indiferencia se prolonga, cuando las ilusiones acaban siempre en decepciones y la falta de normas se convierte en la norma, se produce lo que Durkheim llama suicidio anómico; un tipo de suicidio provocado por la anomia y la exasperación de un individuo que, al considerarse él mismo como la causa propiciadora de su desdicha, decide ir contra sí mismo y acabar con su vida: 
Un hombre que es bruscamente arrojado por debajo de la condición a la que estaba acostumbrado, no puede dejar de exasperarse al sentir escapársele una situación de que se creía dueño, y su exasperación se vuelve naturalmente contra la causa, cualquiera que sea, real o imaginaria, a la que atribuye su ruina. Si él mismo se reconoce como el autor responsable de la catástrofe, la tomará consigo mismo; si no, con otro (DURKHEIM, 2008: 311).

Esto es lo que sucederá con el protagonista de El árbol de la ciencia. Baroja desarrolla la historia de forma que el matrimonio feliz entre Andrés Hurtado y el personaje de Lulú acaba en una auténtica tragedia, cuando ésta le pide tener un hijo y queda embarazada. El niño no deseado por Hurtado nacerá muerto y como consecuencia del mismo parto morirá Lulú. Andrés Hurtado, que durante los últimos años de su vida empieza a consumir morfina, se suicida la noche del mismo día en que había muerto Lulú:

- Vamos a despertarle entonces - dijo Iturrioz.

Entraron en el cuarto. Tendido en la cama, muy pálido, con los labios blancos, estaba Andrés.

- ¡Está muerto! —exclamó Iturrioz.

Sobre la mesilla de noche se veía una copa y un frasco de aconitina cristalizada de Duquesnel.

Andrés se había envenenado. Sin duda, la rapidez de la intoxicación no le produjo convulsiones ni vómitos.

La muerte había sobrevenido por parálisis inmediata del corazón.

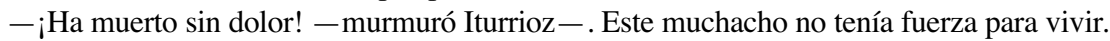
Era un epicúreo, un aristócrata, aunque él no lo creía.

- Pero había en el algo de precursor - murmuró el otro médico (p. 565).

El suicidio anómico será el final previsible de una vida inestable. El individualismo y el pesimismo existencial, unidos a ese talante indolente y a la falta de un plan y un esquema de vida, desembocarán en una muerte anunciada. El suicidio de Andrés Hurtado es un suicidio que, por esperable y poco sorprendente, no inspira al lector una gran tristeza, como reconoció en su día el propio Pío Baroja: «A pesar de su final trágico - escribió Baroja sobre El árbol de la ciencia-, no creo que deje un fondo de melancolía». Por esta sensación de suicidio previsible y casi inevitable, y por todos los motivos que hemos expuesto a lo largo de este trabajo, creo que podemos considerar el caso del suicidio de Andrés Hurtado, protagonista de la novela de Pío Baroja El árbol de la ciencia, un ejemplo concreto, procedente del mundo de la literatura pero inspirado en la realidad de la crisis de fin de siglo española, de lo que Émile Durkheim describe en su obra El suicidio como un suicidio anómico.

\section{CONCLUSIÓN}

La conclusión que se puede extraer de este trabajo - o una de ellas - es que en ocasiones, y como ya hemos señalado al principio del texto, literatura y sociología han coincidido en la elección de un mismo objeto de estudio o de un mismo tema de inspiración, aunque el método mediante el cual se haya abordado este tema haya sido muy distinto. En el caso de la disciplina sociológica, hemos visto que el análisis durkheimiano del fe- 
nómeno social del suicidio se ha estudiado mediante un método más tendente a la generalización y la formulación de teorías globales con un mayor nivel de abstracción. En el caso de la literatura, lo que hemos podido hallar en la novela de Baroja es el intento de recrear en forma de ficción un caso concreto o un ejemplo particular de ese mismo comportamiento y estado mental del individuo moderno al que los sociólogos llamaron «anomia». En este sentido, lo que he pretendido demostrar es que, contrariamente a lo que algunos sociólogos o historiadores de la literatura pueden pensar, existen muchos puntos en común entre la teoría sociológica clásica que estudió la crisis de la sociedad moderna en el tránsito del siglo XIX al XX y ese conjunto de obras que forman lo que para Europa llamamos literatura fin de siècle o de fin de siglo y para España llamamos literatura modernista o literatura de la Generación del 98, según los casos y los gustos. Por esto, $\mathrm{y}$ ahora que se habla tanto - aunque luego se predique poco con el ejemplo - de las ventajas del trabajo y la investigación interdisciplinaria, por el aporte de matices y el abanico de nuevas perspectivas que este diálogo entre diferentes saberes nos puede proporcionar, considero que la relación entre sociología, literatura y, por supuesto, la historia, como disciplina que nos aporta el contexto histórico necesario para cualquier análisis de acontecimientos ocurridos en el pasado, es una relación a tres bandas que, para determinados casos concretos y actuando siempre con las debidas precauciones y con el mínimo rigor exigible, puede resultar tremendamente provechosa para la gente que trabajamos día a día con fuentes literarias y puede contribuir a dar una mayor complejidad y una mayor riqueza interpretativa a los trabajos sobre la novela que filólogos, historiadores y sociólogos, hemos venido haciendo por separado hasta no hace mucho tiempo. 